\title{
Laboreal
}

Volume $11 \mathrm{~N}^{\circ} 1$ | 2015

Modos de vida e trabalho

\section{Modos de vida e trabalho: apresentação do dossiê}

Modos de vida y trabajo: presentación del dossier

Modes de vie et travail: présentation du dossier

Ways of life and work: presentation of the dossier

Mary Yale Neves, Hélder Pordeus Muniz, Maristela Botelho França e Cláudia Osório

\section{OpenEdition}

\section{Journals}

\section{Edição electrónica}

URL: http://journals.openedition.org/laboreal/3941

DOI: 10.4000/laboreal.3941

ISSN: 1646-5237

\section{Editora}

Universidade do Porto

\section{Refêrencia eletrónica}

Mary Yale Neves, Hélder Pordeus Muniz, Maristela Botelho França e Cláudia Osório, « Modos de vida e trabalho: apresentação do dossiê », Laboreal [Online], Volume $11 N^{0} 1$ | 2015, posto online no dia 01 julho 2015, consultado o 24 setembro 2020. URL : http://journals.openedition.org/laboreal/3941 ; DOI : https://doi.org/10.4000/laboreal.3941

\section{Este documento foi criado de forma automática no dia 24 setembro 2020.}

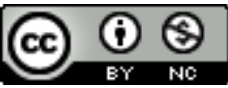

Laboreal está licenciado com uma Licença Creative Commons - Atribuição-NãoComercial 4.0 Internacional. 


\title{
Modos de vida e trabalho: apresentação do dossiê
}

\author{
Modos de vida y trabajo: presentación del dossier \\ Modes de vie et travail: présentation du dossier \\ Ways of life and work: presentation of the dossier \\ Mary Yale Neves, Hélder Pordeus Muniz, Maristela Botelho França e \\ Cláudia Osório
}

\section{NOTA DO EDITOR}

http://dx.doi.org/10.15667/laborealxi0115myn

1 Os diferentes artigos reunidos neste dossiê temático refletem o percurso de uma rede de pesquisadores brasileiros com distintas formações: psicólogos, linguistas, engenheiros e designers. Todos têm como afinidade uma influência marcante das abordagens clínicas do trabalho, entre elas a ergonomia da atividade. Está presente também no grupo uma vinculação com a pesquisa realizada simultaneamente à intervenção em diferentes situações de trabalho, o que tem levantado diversas questões de ordem ética, epistemológica e metodológica. $O$ esforço de enfrentar em conjunto tais questões fez com que esse coletivo decidisse criar no Brasil, no interior da Associação Nacional de Pesquisa e Pós-Graduação em Psicologia - ANPEPP, um Grupo de Trabalho (GT) intitulado Modos de Vida e Trabalho.

2 Esse GT iniciou-se no X Simpósio da ANPEPP em 2004. Sua proposição no âmbito dessa associação resultou, portanto, da interação sistemática - interdisciplinar, multiprofissional, interinstitucional e interestadual - entre esses diversos docentes e pesquisadores, potencializando redes de diálogo e intercâmbio já existentes, processo que remonta ao início dos anos 90 .

3 No movimento de constituição desse GT, consolidou-se o caráter transversal do ponto de vista da atividade para compreender $\leftrightarrow$ transformar os modos de vida e trabalho, 
pautando-se por compromissos éticos, epistêmicos e políticos entre pesquisadores e protagonistas do trabalho em análise.

4 Ao longo dos últimos anos, o grupo vem alcançando uma crescente produção conjunta, na forma de organização de eventos, organização de livros, publicação de artigos e intercâmbios.

Desde 2008 o GT indica um tema central a ser debatido em cada período entre os simpósios da ANPEPP que ocorrem a cada dois anos. Para o XV Simpósio, realizado em maio de 2014, optou-se por uma discussão com ênfase em metodologias de pesquisa, intervenção e formação, debate que vem sendo enfrentado de modo recorrente a partir dos anos 2010.

6 O grupo já havia se decidido em Simpósio anterior pela construção de textos em parcerias acerca dessa temática a serem submetidos a um processo de análise e discussão coletiva. Nessa direção, alguns esboços de artigos foram inicialmente debatidos no II Seminário Nacional sobre Metodologia de Pesquisa em Modos de Vida e Trabalho, promovido pelo GT na Universidade Federal Fluminense, no estado do Rio de Janeiro, em setembro de 2013. Nesse evento, deu-se continuidade à discussão dos artigos no XV Simpósio, de 2014, que contou inclusive com a colaboração de uma pesquisadora externa ao grupo.

7 Pretendeu-se, com esse encaminhamento, melhor refletir acerca dos diferentes dispositivos metodológicos e técnicos em curso nas práticas de pesquisa-intervenção e formação que vêm sendo experimentadas pelos membros do GT. Para tanto, os textos produzidos foram divulgados previamente, de forma que no Simpósio todos já os tinham lido e sobre eles tinham assinalado e enviado para os autores de cada texto os seus comentários e observações. Dessa forma, exercitou-se a produção de artigos (em parceria), por meio da análise crítica e de debates, algo que se configurou como uma modalidade fecunda ao favorecer um maior desenvolvimento coletivo. Como desdobramento dessa experimentação, encaminhou-se a proposta de organização destes materiais sob forma de um dossiê a ser submetido para avaliação dos seus vários textos à Direção da Revista Laboreal.

8 Após as fundamentais interlocuções com os pareceristas, os artigos evoluíram para essa versão final que se apresenta para um público mais abrangente, que poderá ler e realimentar os debates com os autores, que não buscam outra coisa senão ampliar as possibilidades de controvérsias que possam contribuir para o enriquecimento de seus pressupostos teóricos e metodológicos. Não há nenhuma pretensão maior de propor renovações metodológicas, mas sim de socializar reflexões sobre a forma como têm sido realizadas as pesquisas e intervenções pelo grupo. Assim, espera-se que estes textos também sirvam de instrumento para o desenvolvimento do ofício de pesquisadores analistas do trabalho que assumem, como sustenta Schwartz (2010), uma postura de desconforto intelectual, sempre colocando em validação as ferramentas conceituais e metodológicas com as quais estão atuando, já que a atividade humana exige esse repensar permanente de saberes e valores. Estamos certos de que este dossiê é apenas um elo a mais na cadeia de diálogos sobre o trabalho vivo e, como tal, está no front de contra-palavras. 


\section{BIBLIOGRAFIA}

Schwartz, Y. (2010). Trabalho e ergologia. In Y. Schwartz, \& L. Durrive (Orgs.). Trabalho e ergologia: conversas sobre a atividade humana (pp.25-46). $2^{\text {a }}$ ed. rev. e ampl. Niterói: Editora da Universidade Federal Fluminense.

\section{AUTORES}

\section{MARY YALE NEVES}

Grupo de Pesquisas Gestão, Trabalho e Atividade - GESTA, Departamento de Psicologia - Instituto de Psicologia, Universidade Federal Fluminense, Rua Clarice Índio do Brasil, 30 apt 803, Botafogo, CEP 22.230-090, Rio de Janeiro, RJ - Brasil myale@uol.com.br

\section{HÉLDER PORDEUS MUNIZ}

Grupo de Pesquisas Gestão, Trabalho e Atividade - GESTA, Departamento de Psicologia - Instituto de Psicologia, Universidade Federal Fluminense, Rua Pinheiro Machado, 99/508, Laranjeiras, Rio de Janeiro - RJ. Cep 22231-090.

heldermuniz@uol.com.br

\section{MARISTELA BOTELHO FRANÇA}

Grupo de Pesquisa Linguagens, trabalho e atividade de formação, Departamento de Processos Técnico-documentais, Escola de Letras, Universidade Federal do Estado do Rio de Janeiro UNIRIO, Av. Pasteur, 458 sala 413, Rio de Janeiro, RJ - Brasil mbfranca@hotmail.com

\section{CLÁUDIA OSÓRIO}

Núcleo de Estudos e Intervenção em Trabalho e Saúde (NUTRAS), Programa de pós graduação em psicologia, Departamento de Psicologia - Instituto de Psicologia, Universidade Federal Fluminense, Rua São Manuel, 23 apt 201. Botafogo, Rio de Janeiro, RJ - Brasil claudia.osorio.uff@gmail.com 